\title{
Gastroesophageal Reflux Events Occurring During a Meal Can Still Be Temporally Associated With a Symptom Even When Analysis Settings Are Set to Exclude Meals
}

TO THE EDITOR: Combined multichannel intraluminal impedance and $\mathrm{pH}$ monitoring (MII-pH) is becoming the gold standard for assessing gastroesophageal reflux (GER) and for assessing the temporal relationship between GER and symptoms. ${ }^{1-3}$ Using MII$\mathrm{pH}$ reflux measuring systems (like Medical Measurements Systems [MMS]; Amsterdam, The Netherlands), 24-hour MII-pH studies are manually scanned for the presence of GER episodes and for various symptoms that have been recorded over the course of the study. Traditionally, "mealtimes" are excluded from the analysis ${ }^{4}$ so that esophageal acidification that may occur during feeding will not be considered when calculating total esophageal acidification (ie, reflux index) and because rapid swallows can occasionally be misinterpreted as reflux events.

During a recent MII-pH study, we discovered that an impedance-detected non-acid GER episode (occurring at the very end of a feeding period), while not counted among the total MII events, was recognized by the software as having been initiated during the 120 -second pre-symptom window of a cough event that
A

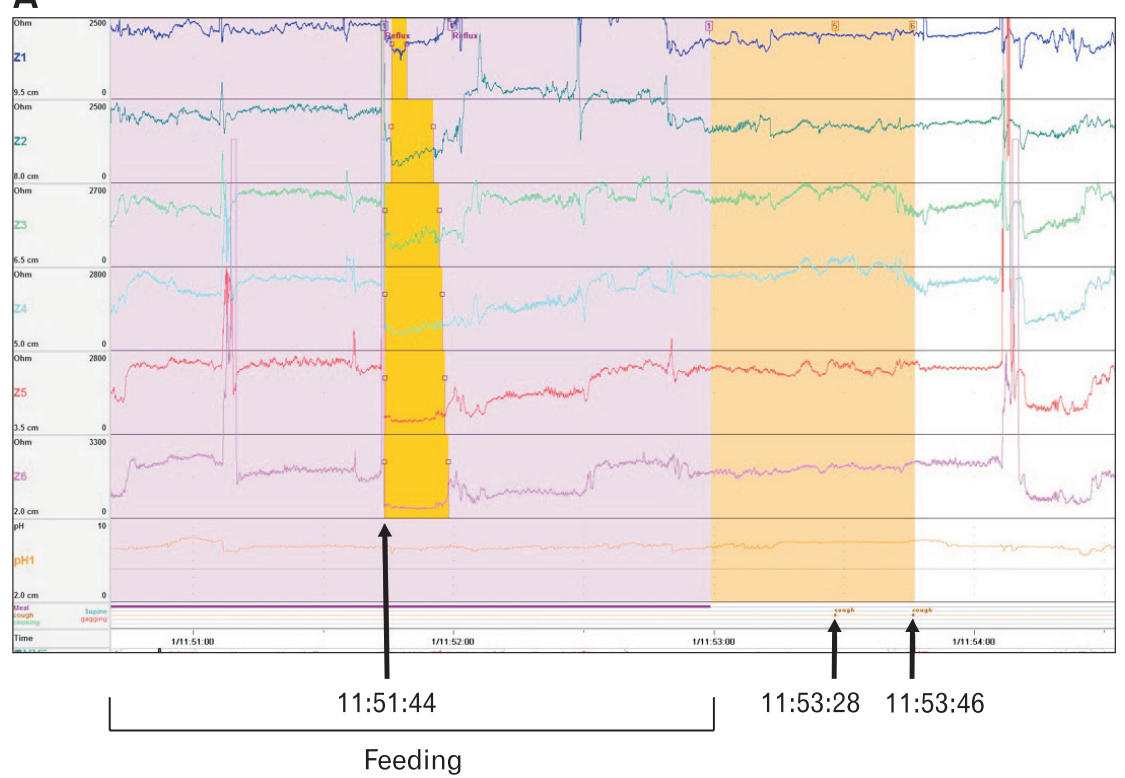

B

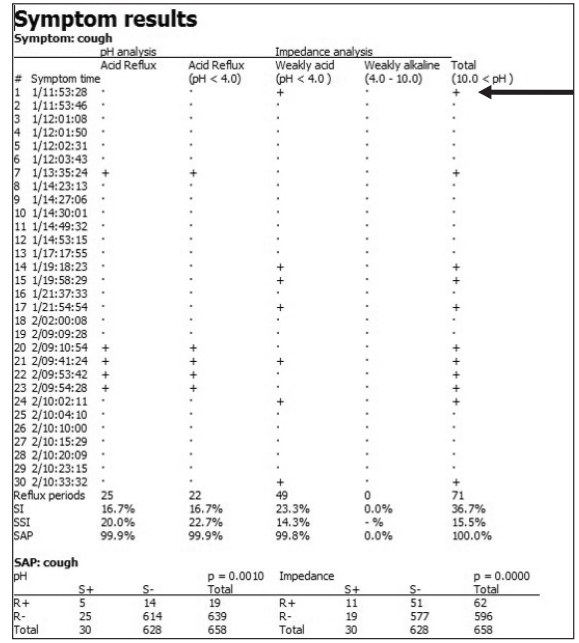

Figure. A symptom-gastroesophageal reflux (GER) association was established involving a GER episode that occurred during a mealtime. The figure above depicts a GER episode (start time 11:51:44) occurring during a feed (Panel A), being tagged and temporally associated with a downstream cough event (11:53:28) (Panel B). The GER (a non-acid event) episode occurred within 2 minutes (96 seconds) just prior to 11:53:28 cough event and 122 seconds ( $>2$ minutes) prior to a second cough event (11:53:46). Note the black arrow in Panel B, indicating the GERassociated 11:53:28 cough event. 
occurred immediately following the meal (Figure). It is important that software users be aware that despite checking the "exclude meal periods" box in the system analysis settings, GER episodes commencing at the end of the feeding period (and within the 120 second pre-symptom window of a symptom ${ }^{5}$ ) will be tagged and used to calculate a symptom association probability value. ${ }^{6}$ The clinical implication of our observation is likely situation-specific but could hold significance in patients for whom a positive symptom association probability value $(\geq 95 \%)^{6}$ depends on the additional symptom-GER association.

Frederick W Woodley ${ }^{1,2,3}$

${ }^{1}$ Motility Center, Nationwide Children's Hospital, Columbus, Ohio, USA; ${ }^{2}$ Department of Gastroenterology, Hepatology and Nutrition, Nationwide Children's Hospital, Columbus, Ohio, USA; and ${ }^{3}$ Department of Pediatrics, The Ohio State University College of Medicine, Columbus,

Ohio, USA

1. Mousa HM, Rosen R, Woodley FW, et al. Esophageal impedance monitoring for gastroesophageal reflux. J Pediatr Gastroenterol Nutr 2011;52:129-139.
2. Shin MS. Esophageal $\mathrm{pH}$ and combined impedance-pH monitoring in children. Pediatr Gastroenterol Hepatol Nutr 2014;17:13-22.

3. Uslu Kızılkan N, Bozkurt MF, Salttk Temizel IN, et al. Comparison of multichannel intraluminal impedance-pH monitoring and reflux scintigraphy in pediatric patients with suspected gastroesophageal reflux. World J Gastroenterol 2016;22:9595-9603.

4. Shay S, Tutuian R, Sifrim D, et al. Twenty-four hour ambulatory simultaneous impedance and $\mathrm{pH}$ monitoring: a multicenter report of normal values from 60 healthy volunteers. Am J Gastroenterol 2004;99:10371043.

5. Woodley FW. A positive reflux-symptom association is not marked when the onset of the reflux episode does not occur within the pre-symptom time window. J Neurogastroenterol Motil 2018;24:324-325.

6. Weusten BL, Roelofs JM, Akkermans LM, Van Berge-Henegouwen GP, Smout AJ. The symptom-association probability: an improved method for symptom analysis of 24-hour esophageal $\mathrm{pH}$ data. Gastroenterology 1994;107:1741-1745.

Financial support: None.

Conflicts of interest: None. 